\title{
Can We Reduce Students' Negative Attitude Towards Math?
}

\author{
Jaime R. S. Fonseca \\ ISCSP - Higher Institute of Social and Political Sciences, \\ Technical University of Lisbon, Portugal
}

jaimefonseca@iscsp.utl.pt

\begin{abstract}
This study concerns the teaching/learning experience of Data Analysis at the Higher Institute of Social and Political Sciences (ISCSP), Technical University of Lisbon, first in Sociology course, and next in Social Communication course. In both cases, Data Analysis subject was teaching/learning of the discipline of Mathematics and Statistics for the Social Sciences.

This study aims to find the effect of the use of new technologies on teaching/learning the Data Analysis subject, and, more than that, it wants to know if this use can reduce the effect of negative experiences when learning Mathematics.

From the used dataset, based on a questionnaire, we first profiled students, based on Latent Class Models; then we concluded that the negative attitude toward Mathematics' learning until the 9 year (compulsory) schooling, influenced their performances on the Quantitative Methods (QM) subject, at the secondary level, but the same did not happened with the Data Analysis' performance at University.
\end{abstract}

Kewords: Teaching/Learning Paradigm, Information and Knowledge Society, Latent Class Models, Information Criteria, Hypotheses Tests.

\section{Introduction}

Sociology and Social Communication students, arriving at this University, regularly are becoming from an area were they learn Mathematics until the 9 years (compulsory) schooling, and QM (an Introduction to Data Analysis) at the tenth year; a few would have Mathematics for the complete secondary schooling (12 years). The management of those different kinds of knowledge in the same classroom could not be a simple task.

The knowledge acquisition leads with complex processes as perception, learning, communication, association and reasoning. If the mixture of these processes can not be easy for who is

Material published as part of this publication, either on-line or in print, is copyrighted by the Informing Science Institute. Permission to make digital or paper copy of part or all of these works for personal or classroom use is granted without fee provided that the copies are not made or distributed for profit or commercial advantage AND that copies 1) bear this notice in full and 2) give the full citation on the first page. It is permissible to abstract these works so long as credit is given. To copy in all other cases or to republish or to post on a server or to redistribute to lists requires specific permission and payment of a fee. Contact Publisher@InformingScience.org to request redistribution permission. teaching, it can be an enormous task for those that are trying the learning.

Concerning teaching, it is well known the heterogeneity of the teachers and researchers community in the area of Statistics/Data Analysis (Batanero \& Godino, 2002), because they are coming from different areas, such as Mathematics, Economy, Engineering, Psychology, and so one. 
Nowadays, it is not possible trying to resist to the new technology use on the knowledge transfer, because in this technological society information and communication, the access to information, the use of data, data analysis and the taking of informed decisions in uncertain situations, form part of the new formative necessities of citizens in the current world (Vallecillos \& Moreno, 2002).

Another additional factor in affecting the students' learning performance is the way they face the knowledge, namely their attitudes to the subject. Such attitudes as profound feelings, relatively stable, are derived from positive or negative experiences across time, on learning the subject (Estrada, 2002).

For this survey students, QM and Mathematics' teachers used the same teaching/ learning methodology, and we aim to know if the negative attitude toward Mathematics did affect students' performance in QM. The teaching/ learning methodology used in the Data Analysis' subject was rather different from the used in QM and Mathematics. Besides, the knowledge of Math's subject is important for a better Data Analysis subject's understanding, and so we aim to know, based on students' performance in Data Analysis, if the negative attitude toward Math still affects the students' performance in Data Analysis.

Summarizing, the mainly goal of this study consists on verifying if using a new teaching/learning methodology, we can eliminate or reduce the effects of students' negative attitude of dislike Math.

\section{Data}

The used dataset on this research work was obtained through the use of a questionnaire. The research was conducted from a sample of 127 students of ISCSP, from Sociology and Social Communication courses, with ages ranging from eighteen to thirty seven years.

We want to know their feelings about Math for evaluating the consequences on teaching/learning QM and Data Analysis, for instance.

The attributes we used on this questionnaire, are: genre, course, like/dislike Mathematics, number of days studying a week, working student, QM results, and age (at the year end, we become knowing their Data Analysis results).

We only use students from these two courses because only they studied the subject of Data Analysis instead of Mathematics, at the discipline of Mathematics and Statistics for Social Sciences, at University first year. They were used the same curriculum, they had the same teacher, they were the same learning/teaching method, and they were used the same technologies.

\section{Teaching Methodology}

The Data Analysis teaching/learning methodology, at ISCSP since year 2000, breaks with past used methodologies on these two courses. The model of new methodology used on this discipline was mainly based on five factors, aiming to an efficient and effective learning:

- Oral exhibition on the foundations and goals of the methods, graphs, calculations, in analysis;

- Oral exhibition with projection, on the ways to proceed with the methods, calculations, graphs, with the software which was used in all of the classes;

- Detailed resolution of applications, accompanied of explanation and analysis, with continuous projection in way to be accompanied by the students, allowing that they wrote down the whole course of the resolution and simultaneously they proceeded to the exhibi- 
tion of doubts; the analysis is always concluded with the discussion and interpretation of the results;

- Resolution of new applications proposal, due to each team work, reserving me the paper of attending individual or collectively, accordingly with the situation;

- Accomplishment of the examination through the use of the computer, in other words, disposing in examination of the same tools which they disposed along with the teaching/learning period.

\section{Latent Class Models and Tests}

Assuming that the ISCSP' students of Sociology and Social Communication can be characterized through a group of typologies that can be considered as resultants of observed variables' combinations, we propose the use of clustering through Latent Class Models, with long tradition in the Social Sciences, introduced by Lazarsfield and Henry (1968), and successively applied, among other, by McCutcheon (1987) and Clogg (1995), to evidence the underlying structure of data.

Latent Class Models intend to justify the associations observed among two or more observed variables, using the relationships of these variables with an underlying latent variable, with two or more classes, according to Marsden (1985).

These statistical models allow us to test if a group of unobserved classes (latent) conveniently justifies the association among the observed variables. In this context, a specific solution, constituted by a group of latent classes, is reasonable when it leads to the minimization of the association among observed variables, inside of each class. This minimization is the result of the basic assumption of independence or conditional independence.

Thus, postulating an heterogeneous population, constituted by $\mathrm{S}$ groups or homogeneous sub populations (latent classes), the latent class model is defined by the variable $\mathrm{Y}$ with $\mathrm{S}$ categories or latent types of students, described through the observed variables, $X_{1}, X_{2}, \ldots, X_{P}$, with $I_{1}, \ldots, I_{P}$ categories, respectively. Let be $\lambda_{i 1 i 2 \ldots i \mathrm{P}}$ the probability for certain individual to belong at the categories $\left(i_{1}, i_{2}, \ldots, i_{\mathrm{P}}\right)$, relatively to the conjoint variable $\left(\mathrm{X}_{1}, \mathrm{X}_{2}, \ldots, \mathrm{X}_{\mathrm{P}}\right)$, with $i_{1}=1, \ldots, \mathrm{I}_{1}, \ldots, i_{\mathrm{P}}=1, \ldots, \mathrm{I}_{\mathrm{P}}$. In these conditions, supposing the existence of a latent variable $\mathrm{Y}$, with $\mathrm{S}$ categories, explaining the relationships among the observed variables, the probability $\lambda_{i 1 i 2 \ldots i \mathrm{P}}$ can be defined by the model

$$
\begin{aligned}
\lambda_{i_{1} i_{2} \ldots i_{\mathrm{P}}}= & \sum_{s=1}^{S} \lambda_{\mathrm{Y}}(s) \lambda \mathrm{X}_{1} \mid \mathrm{Y}=s \\
& \left.\cdots \lambda_{\mathrm{X}_{\mathrm{P}} \mid Y=s}\left(i_{1}\right) \lambda_{\mathrm{P}}\right)
\end{aligned}
$$

where

- $\lambda_{\mathrm{Y}}(s)$ represent the probabilities of $\mathrm{Y}=\mathrm{s}$, probabilities that an individual belongs to the latent class $\mathrm{s}(\mathrm{s}=1 \ldots, \mathrm{S})$, that is, the probabilities of the latent classes, also designated by relative sizes or mixture proportions, which estimate the likelihood that individuals belong to each one of the classes.

$-\lambda \mathrm{X}_{\mathrm{p}} \mid \mathrm{Y}=\mathrm{s}\left(i_{\mathrm{p}}\right), \mathrm{p}=1, \ldots, \mathrm{P}$, represents the conditional probability that the variable $\mathrm{Xp}$ is in the category ip, knowing that the latent variable $\mathrm{Y}$ is in the level s. 
In estimating latent class models, they are of fundamental importance in their structure, the estimates of the probabilities of the latent classes or relative sizes and certain individual's conditional probabilities, to take values in certain categories of the observed variables, given that it is member of a class of the latent variable.

The proportions of the latent classes describe the distribution of probability of the latent classes or typologies; they become useful in the description of the typologies' prevalent inside of the population and in the comparison of prevalent among sub populations.

Relatively to the variables segmentation base used in this study, easily it is verified that for all the same measure (all of them are categorical variable) scale was used and consequently modelled through the distribution multinomial. For a more complete description about the estimation of the latent class models, by maxim likelihood method, through the algorithm EM (ExpectationMaximization): see McLachlan and Peel (2000) and Fonseca and Cardoso (2005) .

Concerning methodologies for the selection of the appropriate latent class model, we propose the use of the traditional information criteria. Especially, because all the observed variables have similar measure, all of them categorical, we will use the information criterion $\mathrm{AIC}_{3}$, the more advised for this situation, accordingly to Fonseca and Cardoso (2007).

The process is begun through the estimate of the model base, or homogeneity model, which supposes the hypothesis of existence of a single latent class to obtain the individuals' appropriate description.

Next we proceed to the estimate of models that need two latent classes to describe the individuals conveniently and so forth, for incrementing the unit in relation to the value of $\mathrm{S}$, number of latent classes, until the inclusion of a new latent class is not relevant. This value of $\mathrm{S}$ will be detected through the minimization of $\mathrm{AIC}_{3}$.

The methodology of the hypotheses tests will be basically used to test if the students' negative attitude (liking or disliking Mathematics) toward Mathematics, it is decisive relatively to the performance in the learning of the subject of both QM and Data Analysis.

\section{Data analysis and results}

\section{Students Profile}

This study began with the investigation of the data structure, since the respective knowledge will lead to the students' characterization, through the considered attributes. It is about testing the hypothesis of the students' population to be homogeneous, that is to say, the students are all similar in agreement with the used attributes for their description, against the hypothesis of there being more than a homogeneous class. The latent class models estimation led to results of information criterion which we report on table 1.

Table 1: Information criterion results

\begin{tabular}{ccc}
\hline \hline Latent class & AIC3 & $\mathrm{E}_{\mathrm{s}}$ \\
\hline 1 & 2905,993 & - \\
2 & 2695,388 & 0,819 \\
3 & 2663,261 & 0,858 \\
\hline \hline
\end{tabular}


As can be seen, in Table 1, the solution consists of two latent classes. It means that the homogeneity hypothesis was rejected, thus existing two classes perfectly identified, accordingly with the used information criterion.

Table 2 : Students' profile

\begin{tabular}{lcc}
\hline \hline Attributes & $\begin{array}{c}\text { Like Math } \\
\text { Students (67\%) }\end{array}$ & $\begin{array}{c}\text { Dislike Math } \\
\text { Students (33\%) }\end{array}$ \\
\hline Gender & Male & Female \\
Age & Mean: 20 & Mean: 25 \\
$\begin{array}{l}\text { Course } \\
\text { Like/Dislike }\end{array}$ & S. Communication & Sociology \\
$\begin{array}{l}\text { Mathematics } \\
\text { Times of } \\
\text { week study }\end{array}$ & Yes & No \\
$\begin{array}{l}\text { Working } \\
\text { student }\end{array}$ & No & One or three \\
$\begin{array}{l}\text { QM results } \\
\begin{array}{l}\text { Data Analy- } \\
\text { sis results }\end{array}\end{array}$ & Mean: 15.7 & Yes \\
\hline \hline
\end{tabular}

Based on that solution, the students' profile can be drawn, and it is displayed in Table 2. According to the drawn profile, the classes could be named as Students' Like math, in the class 1 and Students' Dislike Math, in the class 2.

\section{Data Analysis by Course}

After the students' characterization, we made comparisons of their mean performances on Data Analysis - by course.

Because the Kolmogorov-Smirnov test (Lilliefors, 1967; Fonseca, 2001), did reject the null hypothesis of normality of Social Communication and Sociology students' results ( $\mathrm{p}$-value $=0.003$ and $p$-value $=0$, respectively), it was used the non-parametric test of Mann and Whitney (1947) to proceed to the comparison of the distributions of the Data Analysis students' results, by course.

The null hypothesis of equality of distributions was rejected ( $p$-value $=0.043$ ), and we concluded by the existence of enough evidence on data to state that the average of the obtained Data Analysis students' results on Sociology is different from the average of the obtained Data Analysis students' results on Social Communication.

\section{QM toward Attitude}

In the sense of discovering if the students' feelings toward Mathematics will affect the QM students' results, we did proceed on the comparison of the QM results' means, as they like or dislike Mathematics.

Because of the test of Kolmogorov-Smirnov did reject the null hypothesis of normality of the QM students' results knowing that they like Mathematics ( $p$-value $=0.002)$, the test of Mann-Whitney was used to proceed to the comparison of the means of the results, as the feeling for the Mathematics. 
The null hypothesis of equality of the distributions was rejected ( $p$-value $=0.028$ ), then being concluded that the feeling toward Mathematics did affect the means performance of the students in QM.

\section{Data Analysis toward Attitude}

When comparing the means of the classifications obtained by the students in the discipline of Data Analysis, as the manifested attitude in relation to the Mathematics, the results were shown encouraging in relation to the used teaching/learning strategy.

The test of Kolmogorov-Smirnov rejected the null hypothesis of normality of the Data Analysis students' results, independently of the attitude toward Mathematics ( $p$-value $=0$, for both of like or dislike Mathematics); then it was used the test of Mann-Whitney to proceed to the comparison of the Data Analysis students' means results, in the referred conditions.

The null hypothesis of equality of the distributions was not rejected ( $\mathrm{p}$-value $=0.074$ ), and so we concluded that there was not enough evidence in the data in order to affirm that the negative attitude toward Mathematics did affect the students' Data Analysis performance. We do not have doubts that the methodology used was the main responsible for the annulment of that disadvantage.

\section{Conclusions}

By analyzing the data, initially we concluded by select a two-class model, and in accordance with the attributes, we name them as Like Math (Social Communication) and Dislike math (Sociology) students. Moreover, we concluded that the average data Analysis results were different in the two classes.

All of the strategies used by teachers, including transforming information, are doing so that their students will learn more, and they make important decisions regarding the kind of instruction they employ in their classroom, as well as the used policies and procedures (Gordon, Dembo \& Hocevar, 2007). The information about the students' attitude that was made available to us, at the beginning of the year, it was very important for the teaching/learning approach of Data Analysis subject, supposedly the continuity of the matters transmitted to the students in the discipline of QM.

It was known the students' percentage that did not like Mathematics (42\%) and, much more important, it was known that this feeling had determined that the means of the QM students' results had been different. Then, it was this added challenge of annulling that disadvantage, when teaching/learning Data Analysis subject.

The traditional teaching/learning approach used for teaching/learning QM subject did that QM and Mathematics were quite similar for students, and so they probably transfer to QM their negative attitudes; the test results confirm that the negative attitude toward Mathematics had been influenced negatively the QM results.

This study explored the knowledge of the students' negative attitude toward Mathematics, in advance; naturally, this knowledge would influence the teacher strategy in his classroom. Indeed, his teaching practices would try not overwhelming students with big equations, theorems, and so one.

They need to know how to analyse data, and so the aforesaid strategy was delineated in order to motivate and influence students on their learning and understanding of the Data Analysis subject, with computers and software as support. 
Nowadays, the education's technology supplies to all of us a great variety of strategies for the teaching (Godino, Ruiz, Gnaw, Pareja, \& Recio, 2002), in general, and for Data Analysis in particular. Even though apparently a paradox, there is a great number of students that approach information technology as a "necessarily evil", or at least, as a required tool that is of difficult use (Dougherty, Kock, Sandas, \& Aiken, 2002).

Indeed, this study also shows the initial discomfort of some students, regarding the computer use as a tool; however it was unsurprising that as they used more and more the computers, they also feel more and more comfortable.

Trying to understand the impact of learning Math on future topics, such as MQ and Data Analysis, after all we concluded that the students' negative attitude toward Mathematics did affect their performance on QM, but it did not affect their performance on Data Analysis. Math and QM teaching/ learning methodology was the same, much more theoretical than practice, and students who did not like Math tend not liking QM.

In fact, we think that the used methodology in teaching/learning Statistics subject was the main responsible for good results. We think that the development of some basic learning skills such as time planning, reading, team work or oral presentation also contribute for their attitude toward knowledge acquisition.

The new technologies will change the teaching style and the learning style drastically: thus, the teachers must not just be "transmitters of information" and the students will stop being just "receivers of information".

According to Watson (2001), the technological information should not just be understood as a catalyst for the change; she should lead to changes of the teaching styles, of the approaches to the learning and of the access to the information.

Unfortunately, the majority students' non response to the question which intended to address the issue why they dislike Math, invalidate other studies. In the future we intend to approach again this issue, and we hope we can have more success.

We also hope we can test the used teaching/learning methodology, in the future, using a sample with great size.

\section{Acknowledgements}

The author thanks the three anonymous referees for valuable feedback on earlier version of the paper.

\section{References}

Batanero, C. \& Godino, J. D. (2002). Training future researchers in statistics education: Reflections from the Spanish experience, ICOTS6.

Clogg, C. C. (1995). Latent class models. In G. Arminger, C.C. Clogg, \& M.E. Sobel (Eds.), Handbook of statistical modeling for the social and behavioral sciences (pp. 311-359). New York: Plenum.

Estrada, A. (2002). Análisis de las actitudes y conocimientos estadísticos elementales en la formación del profesorado, PhD., (Universidad Autónoma de Barcelona).

Fonseca, J.R.S. (2001). Estatística matemática (Edições Sílabo, Lisboa).

Fonseca, J.R.S. \& Cardoso, M.G.M.S. (2005). Retail clients latent segments. In Carlos Bento Proceedings, Amílcar Cardoso, Gaël Dias (Eds), 12th Portuguese Conference on Artificial Intelligence, EPIA 2005 (Springer-Verlag, Covilhã, Portugal). 
Fonseca, J.R.S. \& Cardoso, M.G.M.S. (2007). Mixture-model cluster analysis using information theoretical criteria. Intelligent Data Analysis, 11, (in press).

Gordon, S. C., Dembo, M.H. \& Hocevar, D. (2007). Do teacher's own learning behaviors influence their classroom goal orientation and control ideology? Teaching and Teacher Education, 23, 36-46.

Lazarsfield, P.F. \& Henry, N.W. (1968). Latent structure analysis. Boston: Houghton Mifflin.

Lilliefors, H. W. (1967). On the Kolmogorov-Smirnov test for normality with mean and variance unknown. Journal of the American Statistical Association, 62, 399-402.

Mann, H. B. \& Whitney, D. R. (1947). On a test of whether one of two random variables is stochastically larger than the other. The Annals of Mathematical Statistics, 50-60.

McCutcheon, A.L. (1987). Latent class analysis. Sage University Paper. Newbury Park: Sage Publications.

McLachlan, G.F. \& Peel, D. (2000). Finite mixture models. John Wiley \& Sons.

Vallecillos, A. \& Moreno, A. (2002). Framework for instruction and assessment on elementary inferential statistics thinking, teaching of mathematics. Crete, Greece, July 1-6, 2002.

Watson, D. M. (2001) Pedagogy before technology: Re-thinking the relationship between ICT and Teaching, Educational and Information Technologies, 6, 251-266.

\section{Biography}

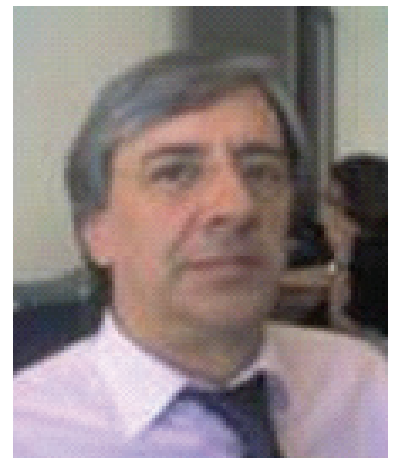

Jaime R. S. Fonseca is currently an Assistant in the ISCSP-Higher Institute of Social and Political Sciences, Technical University of Lisbon, teaching Data Analysis with computer in the classroom, researcher in the CAPP- Centre for Public Administration and Policies, and is a doctoral candidate in the ISCTE-Business School, Department of Quantitative Methods, Lisbon, Portugal. 